\title{
Analysis of Social and Emotional Development of Orphaned Youth in terms of Self Concept and Resilience: Study at Child Care Children's Home (PSAA) Tunas Bangsa Pati
}

\author{
Santoso $^{* a}$, Edris Zamronia \\ [a] University of Muria Kudus, Indonesia \\ *santoso.bk@umk.ac.id
}

\begin{abstract}
The purpose of this study is to describe the development of the Young Social and Emotional Self-concept and in terms of resilience in the PSAA Tunas Bangsa Pati. The method used is descriptive research with development studies dab types of data obtained will be analyzed by the cross sectional method. The results showed that the concept of self-possessed teenager PSAA is not good, it can be seen from the description of several indicators of self-concept which suggests that adolescents assessment of him is not good because many feel insecure and feel inferior. Viewed from the aspect of resilience, generally adolescents PSAA good enough. It can be seen from the emotion management capabilities of any events that are considered less fun in.
\end{abstract}

Keywords: social development; emotional development; resilience; self-concept

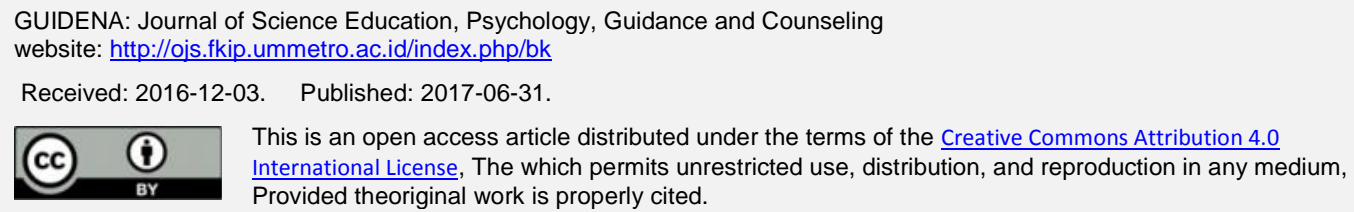




\section{INTRODUCTION}

Growth is a process through which a person during his development. In connection with the development of youth, we need to realize that the process of development that happens through experience in learning. Parents, teachers, and other educators who are responsible for adolescent development tasks need to understand child development and how to serve children who are experiencing growth. Moreover, issues related to the social development of adolescents is a matter that needs to be understood by both teachers and people in charge of educating adolescents, because of social development is very important for personal development and learning achievement adolescence.

Teens are developing wellis a task that must be mastered is the development of relationships with peers or with adults other than teachers and parents. Teenagers can perform optimally in the study if he is accepted and admired in his peer group and be able to solve social problems as well as adults, especially parents and other adults. Juvenile social behavior is influenced by various factors such as peers, parents, siblings, teachers, cognitive development, and self-concept. Therefore, in this paper, we will discuss the social development of adolescents.

In addition to social development, children also experience emotional development into adolescence. Emotional development in adolescents is marked by unstable emotions and tumultuous. At this time the mood (mood) can change very quickly. Research in Chicago by Mihalyi and Reed Larson (1984) found that the average teenager requires only 45 minutes for the change of mood "extraordinarily pleased" to "exceptional sad", while adults take several hours for the same thing. These emotional changes closely related to the maturity of hormones that occurs in adolescents. Emotional stress arising from the physical changes that occur rapidly and widely during puberty.

Emotional development in adolescents is marked by unstable emotions and tumultuous. At this time the mood (mood) can change very quickly. Research in Chicago by Mihalyi and Reed Larson (1984) found that the average teenager requires only 45 minutes for the change of mood "extraordinarily pleased" to "exceptional sad", while adults take several hours for the same thing. These emotional changes closely related to the maturity of hormones that occurs in adolescents. Emotional stress arising from a change of physical rapid and extensive that occur during puberty.

A number of studies on adolescent emotions show that their emotional development depends on the maturity factors and learning factors. Maturity and learning are closely intertwined with one another to influence the emotional development. Intellectual development results in the ability to understand the meaning of that previously did not understand where it creates an emotional focus on a single object. The ability to recall also affects the emotional reaction. And it causes children to become reactive to stimuli that previously did not affect them at a younger age. Learning activities also support the emotional development. This context embraces opportunities for environmental influence in affecting the social and emotional development of the individual.

Some of the things that support the social and emotional development are the concept of self and resilience. The concept of self is all ideas, thoughts, beliefs and individual establishments known about him and affect individuals in their dealings with others. The concept of self is our mental computer operating system. The concept of selfdetermine our performance. Level of selfconcept determines the level of achievement of life. The concept of self in adolescents generally still unstable. Usually, they assess their personality in accordance with the desire of the groups in which they are located, they still rely on the peer group. time adolescence is a stage of transition from childhood to adulthood is marked by changes both in terms of physical, social and psychological. Such changes lead to the attempt to discover the identity or identity. Efforts to find the identity associated with how teens to show himself. They want to be recognized as part of the teen community in general and specifically part of their peer group. The recognition for the sake of teenagers is often willing to make efforts though perhaps it is not something that is necessary or useful to 
them when viewed from the glass eyes of a parent or other adult.

While Resilience is the capacity of one's own humane and useful to address, strengthen itself or even change unpleasant living conditions (traumatic) becomes a natural thing to overcome (Juke, 2003: 63). In the difficult living conditions, as now, people are often faced with various obstacles which may not be circumvented. In other words, individuals are often faced with a variety of events and the harsh reality that they do not really want. People who have the good resilience to understand that failure is not the end of everything. They do not feel embarrassed if unsuccessful. Peoplewith high resilience capable of taking wisdom behind the failure, and they use the experience to build the ideals higher. They are not the type to search the danger, but they do not easily escape when at risk or face dangerous situations (Reivich and Shatte, 2002: 4).

Child development is still a health problem with a fairly high incidence. research in the United States showed that $13 \%$ of children experiencing developmental problems, one in Indonesia, while as mall-scale study conducted in Bandung Regency showed 19\% children experiencing developmental problems. 2 Detecting problems early development is a challenge for health workers, especially for pediatricians.

Ministry of Health in collaboration with the Indonesian Pediatric Association or IDAI has compiled questionnaires pre instruments- development (KPSP) and questionnaires emotional mental problems (KMME) for the early detection of children's growth schedule routine detection performed every 6 months in children aged 36-72 months. In the instrument, there is a division on schedule according to the stages of child development are age 36-48 months, 48-60 months and 60-72 months. 3 The influence of the environment and the mental health of parents on child development is very large, the state of a child can not be cared for by parents is needed orphanage who is responsible for fulfilling the fulfillment of their rights. Several studies have been conducted to ascertain the developmental and emotional problems in children who live with their parents or living in orphanages, as research by Kahn that show emotional and behavioral difficulties of children who were raised by parents who have mental problems. Adopted children, showing growth retardation and language and cognitive abilities are relatively lower.

Interaction with how to play very important because $25 \%$ of children's daily activity is playing. Research has been done in an orphanage in European countries and the United States showed that only $27-53 \%$ of the time play was conducted with caregivers. Another study stated very important interaction and play for 90 minutes each day (describes the use of toys, singing along, talking with kids) to improve child development. Studies comparing developmental problems as well as the factors that influence the development of mental and emotional problems with qualitative methods in children reared in orphanages.

Developments that occurred during the child gets care at home is different from what happened under the care of the biological parents. At least when viewed from upbringing and environment-forming and which affect learning, will affect the formation and development of the social and emotionalteens. Well, when viewed from the aspect of selfconcept and of resilience. It is also possible for foster children in the Child Care Social Institution (PSAA) Tunas Bangsa Pati.

\section{METHOD}

Referring to the purpose of the study is to determine the Social and Emotional Development of Adolescent Orphanage Judging from Self Concept and Resilience In Foster Citizens Social Orphan Children (PSAA) Tunas Bangsa Pati, this study used qualitative descriptive models. This study used qualitative methods are used in an integrated and mutually supportive. A qualitative approach was used to provide an overview of the Social and Emotional Development of Adolescent Orphanage Judging from Self Concept and Resilience In Foster Citizens Social Orphan Children (PSAA) Tunas Bangsa Pati.

Descriptive analysis methods implemented to describe a systematic, factual, accurate, about the facts and the properties associated with the substance of the research. In this case carried out to analyze the Social 
and Emotional Development of Adolescent Orphanage Judging from Self Concept and Resilience In Foster Citizens Social Orphan Children (PSAA) Tunas Bangsa Pati. The analytical method used based on development studies. Research conducted to obtain reliable information about how the properties of children at different ages, how their differences in the levels of that age, and how they grow and develop. This is usually done by the method of longitudinal and cross-sectional method.

The cross-sectional method more done than the longitudinal study because it is simpler and cheaper. In a cross-sectional study, the researchers only observed phenomena at one point in time. In the exploratory study, descriptive, or, cross-sectional study was able to explain the relationship of one variable with another variable in the population studied, testedthe function of a model or hypothesis formulation and the degree of difference between the sampling group at one point in time.

\section{RESULT AND DISCUSSION}

Subject observations totaling 3 teenagers who represent the characteristics of the age levels 14,15 and 16 years of age or class $\mathrm{X}, \mathrm{XI}$ and XII secondary school. The boys are the initials SJ, AAR, and NRW. Observations were made to determine the three aspects of social development emotional juvenile, adolescent resilience, and adolescent selfconcept. The observed indicators are as follows:

\section{Social and Emotional development Teens}

Aspects of social and emotional development of adolescents who were observed were as follows:

a. The ability to understand others

b. Have a tendency to establish relationships with others

c. Love to hang out in groups

d. Having conformity in touch with peers

e. Tend many moody and predictable

f. Vulgarian to cover the shortfall in terms of confidence

g. Anger is common

h. Tend not tolerant of others and wanted to always win themselves

i. Start observing their parents and their teachers objectively j. Have a tendency to rebel

$k$. Many teenagers in conflict with their parents

l. Often daydream, think about their future

\section{resilience Youth}

Aspects of adolescent resilience observed were as follows:

a. The ability to regulate emotions (emotion regulation),

b. Ability to control impulse (impulse control),

c. An optimistic attitude in every respect

d. Being able to analyze the cause of an incident

e. Being able to analyze the result of a behavior

f. Empathy in the neighborhood

g. Self-efficacy (self-efficacy)

h. The mindset that reaches the future / think about the future (Reaching out)

\section{Adolescent Self Concept}

Aspects of self-concept were observed in this study are as follows:

a. Feel unsure or believe to cope with her problems.

b. Feel equal to others (not to feel inferior or arrogant in dealing others).

c. Can praise others naturally.

d. Able to repair itself if it fails.

e. Have concern for the interests of others.

f. Do not want to be criticizing other people, like angry when criticized.

g. Like praise others.

h. Like disparaging or criticizing others.

i. Feeling unwelcome, rejected or not considered anyone else, so it is less able to close the friends.

j. Being pessimistic about the competence such as the desire to compete with others in making achievements

The observations on the subject acquired a conclusion as follows:

\section{Social and emotional development of adolescents}

Some psychological barriers found mainly related to the social development of emotional teenagers. The significant behavioral tendency of students to be alone and quiet and tend to withdraw from social surroundings, especially at school. Also found students 
symptoms often moody when asked what his future plans.

\section{resilience teen}

The average teenager who observed lack good emotional control so easily clouded when she got problems especially personal attack. In addition, they are also less able to analyze what causes teens experiencing this problem and how to solve it. However, they are prone to accept criticism even if such criticism is sometimes hurt their feelings.

\section{Adolescent self-concept}

The results showed inferior attitude is very pronounced if the student is in school. Low self-esteem is very thick seen from the way the students hanging out at school. The confidence of the subject is also seen very low. Besides teenagers also looks pessimistic when asked about the future.

Emotional development in adolescents is marked by unstable emotions and tumultuous. At this time the mood (mood) can change very quickly. Research in Chicago by Mihalyi and Reed Larson (1984) found that the average teenager requires only 45 minutes for the change of mood "extraordinarily pleased" to "exceptional sad", while adults take several hours for the same thing. These emotional changes closely related to the maturity of hormones that occurs in adolescents. Emotional stress arising from a change of physical rapid and extensive that occur during puberty.

A number of studies on adolescent emotions show that their emotional development depends on the maturity factors and learning factors. Maturity and learning are closely intertwined with one another to influence the emotional development. Intellectual development results in the ability to understand the meaning of that previously did not understand where it creates an emotional focus on a single object. The ability to recall also affects the emotional reaction. And it causes children to become reactive to stimuli that previously did not affect them at a younger age. Learning activities also support the emotional development. This context embraces opportunities for environmental influence in affecting the social and emotional development of the individual.
Some of the things that support the social and emotional development are the concept of self and resilience. The concept of self is all ideas, thoughts, beliefs and individual establishments known about him andaffect the individual in dealing with others. The concept of self is our mental computer operating system. The concept of self-determine our performance. Level of self-concept determines the level of achievement of life. The concept of self in adolescents generally still unstable. Usually, they assess their personality in accordance with the desire of the groups in which they are located, they still rely on the peer group. Adolescence is a stage of transition from childhood to adulthood is marked by changes both in terms of physical, social and psychological. Such changes lead to the attempt to discover the identity or identity. Efforts to find the identity associated with how teens to show himself. They want to be recognized as part of the teen community in general and specifically part of their peer group.

Adolescence is traditionally regarded as a period of "storm and stress", a period in which the emotional tension rising as a result of physical changes and glands. emotion especially for boys and girls under social pressure and face new conditions, whereas during childhood he was less prepared to deal with the circumstances. Not all adolescents experience a period of storm and stress. But it is also true when most teens experience instability from time to time as a consequence of the effort of adjustment to the new behavior patterns and new social expectations. (Hurlock, 2002: 213). Basically, adolescence is a critical period for the formation of personality. crimes, including abuse of drugs/narcotics and sexual behavior.

Resilience is the capacity of one's own humane and useful for face, strengthen themselves or even change unpleasant living conditions (traumatic) becomes a natural thing to overcome (Juke, 2003: 63). In the difficult living conditions, as now, people are often faced with various obstacles which may not be circumvented. In other words, individuals are often faced with a variety of events and the harsh reality that they do not really want. People who have the good resilience to understand that failure is not the end of everything. They do not feel embarrassed if 
unsuccessful. People who were able to take the wisdom behind the resilience of failure, and they use the experience to build the ideals higher. They are not the type of search hazards,

Child development is still a health problem with a fairly high incidence. research in the United States showed that 13\% of children experiencing developmental problems, one in Indonesia, while as mall-scale study conducted in Bandung Regency showed 19\% children experiencing developmental problems. 2 Detecting problems early development is a challenge for health workers, especially for pediatricians.

Assessment of the self is the extent to which individuals like themselves. The results of self-assessment are referred to as selfesteem. The greater the discrepancy between knowledge and expectations of lower selfesteem (Rogers 1959, Higgins et al, 1985, in Calhoun, JF, 2002). The concept of self is a reflection of what the individual point of view within the individual's own (Patton, 2002). The concept itself is a stable organization and character composed of perception - the perception that seems for the individuals concerned as fundamental.

Of the opinion that the concept of self can be concluded that the views of the individual against himself, which is very consistent and fundamental as the foundation of the individual to interact with others. If the self-concept is less good in peopleitself or lack of confidence, it can make people less able to control me in the association. Likewise, if individuals feel confident with its potential, then the person will be accepted socially.

In the context of social and emotional development, resilience and adolescent selfconcept is one of the parameters that can be used to measure the extent to which social and emotional development of individuals can develop properly or not. The self-concept shows the attitude of an individual to judge for itself, including in terms of idealism about what should be owned by him, a picture of how infuture and self-confidence to face life events. This includes on how her abilities in a relationship or interact with the surrounding environment. How people judge herself, between social life with the surrounding environment.
In another aspect, the resilience will reflect how much a person's emotional maturity to deal with situations that are not always pleasant in his personal life. resiliencesomeone will show how much the ability of individuals in the face of unpleasant events, the ability to control and regulate their emotions, controlling impulses which tend to be destructive, optimism for the events that critically, analyze the causes and consequences of an event experienced, positive attitudes such as empathy, sympathy and respect, selfconfidence and constructive mindset to build a future that is a reflection of a person's emotional maturity.

PSAA research results indicate that the substantial influence one's development environment that can affect the level of resilience and self-concept that is owned by someone, contributing to the impact on a person's social and emotional development. In other words, a good environment one's progress in creating a situation to develop, resilience andself-concept will develop well so that also affects a person's social and emotional development. Flexible power, mindset and a good self-concept reflect the extent to which individuals develop well socially interact with the surrounding environment as well as the extent to which individuals develop properly manage your emotions when faced with events that are not always fun in one's life.

\section{CONCLUSION}

Based on the research results through observation and discussion presented, it can be concluded that in general, the concept of selfpossessed teenager PSAA is not good, it can be seen from the description of several indicators of self-concept which suggests that assessment of adolescents about her poorly because many feel insecure and feel inferior. In terms ofresilience aspect, in general, pretty good PSAA teenagers. It can be seen from the emotion management capabilities of any events that are considered less fun in. So overall it can be concluded that the development of adolescent PSAA unfavorable social and emotional development PSAA good enough if the terms of the concept of self and resilience. 
The PSAA for social workers is expected to further increase the focus on the social and emotional development of adolescents. It is based on research that shows if viewed from the aspect of resilience and selfconcept teen, looks less well developed. Many factors affect, but if the attention and assistance were given optimum, problems with social and emotional aspects of the development of juvenile homes can be resolved. In addition, the institution is expected to provide a growing environment conducive to the development of social and emotional aspects of adolescence.

\section{REFERENCES}

Arikunto, S. (2005). Manejemen Research. Jakarta: Rineka Reserved.

Cormier, WH \& Cormier, LS (1985). Interviewing Strategies for Helpers: Fundamental Skills Cognitive Behavioral Interventions. Monterey, California: Brooks / Cole Publishing Company.

Nevid, JSR and Greene B. (2005). Abnormal Psychology, Fifth Edition Volume 1. Jakarta: Publisher Salemba.

Dobson, D., \& Dobson, KS (2009). EvidenceBased Practice of CognitiveBehavioral Therapy. New York: Guilford Press.

Ghufron, N. and Rini Risnawati. (2010). Theories of Psychology. Yogyakarta: Arruz Media.

Janah, NF (2013). Effect of Counseling Services tiem In Meredukasi Academic Procrastination. Thesis (Unpublished). Semarang: Semarang PGRI University.

Kristanti, Y. avoid Postpone Work Habits. Psikologo Plus Magazine Volume II \# 10. April 2008 edition.

Ramli, M. (2005). Cognitive Behavioral Therapy and Counseling in Education in the Global Era. Bandung: Rizqi Press.

Sukiman. (2011). Class Action Research for Teachers Advisors. Yogyakarta:

Paramitra Publishing.
Sugiyono. (2009). Qualitative and Quantitative Research Methods R \& D. Bandung: Alfabeta.

Utaminigsih, S. (2012). Type Kribadian And Academic Procrastination At Junior 'VIII Tangerang. Thesis (Unpublished). Jakarta: Esa Unggul University.

Wahyuningsih, E. (2011). Effectiveness Guidance Services Group In Fighting Behavior Academic Procrastination (delay task). Thesis (Unpublished). Semarang: Semarang PGRI University. 